\title{
Computational Aspects of (E)-O-Carbomethoxy Methyl Oxime Ether of 1,3-Dimethyl-2,6-Diphenylpiperidin-4-One
}

\author{
N. Sankara Pandian, B. Siva Prakash, M. Thillai Natarajan, C. Ramalingan, M. Velayutham \\ Pillai
}

\begin{abstract}
Density Functional Theoretical (DFT) studies on the biologically active oxime ether derived from 1,3-dimethyl-2,6-diphenylpiperidin-4-one has been carried out. Various quantum chemical parameters of the molecule viz. molecular geometry, Highest Occupied Molecular Orbital Lowest Unoccupied Molecular Orbital (HOMO-LUMO) energies, Non-Linear Optical (NLO) properties, Mulliken atomic charge distribution were obtained theoretically and compared with the single crystal data. An insight into the structure and property correlation revealed the probable behavior of the molecule studied.
\end{abstract}

Keywords: About four key words or phrases in alphabetical order, separated by commas.

\section{INTRODUCTION}

Heterocyclic compounds containing nitrogen atom constitute the backbone of bioactive molecules belonging both aromatic and aliphatic systems such as aziridine, azetidine, pyrrolidine, pyridine, pyrimidine, and piperidine. Of a number of saturated heterocycles available, piperidine functional group forms a large number of biologically active derivatives which are having many applications in the field of agricultural chemistry, medicinal chemistry, material chemistry and others. Piperidine nucleus is present in many alkaloids widely accepted as drugs in nature itself. Mannich condensation of aldehydes, ketone and primary amines/ammonium acetate leads to the birth of many substituted piperidine derivatives. Biological significance of

Revised Manuscript Received on December 15, 2019.

* Correspondence Author

N. Sankara Pandian, Department of Chemistry, School of Advanced Sciences, Kalasalingam Academy of Research and Education (Deemed to be University), Krishnankovil-626126, Tamil Nadu, India.. Email: sankarchemistry2016@gmail.com

B. Siva Prakash, Department of Chemistry, School of Advanced Sciences, Kalasalingam Academy of Research and Education (Deemed to be University), Krishnankovil-626126, Tamil Nadu, India. Email: sivaprakash132770@gmail.com

M. Thillai Natarajan ${ }^{\mathbf{a}, \mathbf{b}}$, a Department of Chemistry, School of Advanced Sciences, Kalasalingam Academy of Research and Education (Deemed to be University), Krishnankovil-626126, Tamil Nadu, India.

b Department of Chemistry, School of Chemical Sciences, Bharathiar University, Coimbatore641046, Tamil Nadu, India. Email: thillairajan687@gmail.com

C. Ramalingan, Department of Chemistry, School of Advanced Sciences, Kalasalingam Academy of Research and Education (Deemed to be University), Krishnankovil-626126, Tamil Nadu, India. Email: ramalinganc@gmail.com

M. Velayutham Pillai*, Department of Chemistry, School of Advanced Sciences, Kalasalingam Academy of Research and Education (Deemed to be University), Krishnankovil-626126, Tamil Nadu, India. Email: cmvpillai@gmail.com; m.velayuthampillai@klu.ac.in.

these synthesized molecules has also been evaluated through in vivo as well as in vitro assay procedures.

4-Piperidone is an important drug derivative as well as an intermediate in the synthetic route of certain chemicals and pharmaceutical drugs [1-2] such as fentanyl, and its analogues carfentanyl and ramifentanyl. Further, molecules possessing 4-piperidone nucleus show desirable biological properties viz. antiviral [3], antitumor [4], central nervous system stimulant [5], analgesic [6], anticancer [7] and antimicrobial activity [8].

Oximes and oxime ethers have significance in medicinal chemistry due to their applications such as medicines and pesticides [9]. These functional groups are prevalent in many medicinally important molecules used as antibiotics (e.g. gemifloxacin mesylate), drugs used in the treatment of organophosphate poisoning viz. pralidoxime chloride, obidoxime chloride etc. caused by insecticides such as malathion and diazinon. An antidepressant drug, fluvoxamine, used as the selective serotonin reuptake inhibitors (SSRIs) also possesses oxime ether functionality in its structure. Both $O$-alkyl and $O$-aryl oximes have been proved to be stable at physiological $p \mathrm{H}$ and $O$-alkyl oxime core is found to be present in a number of approved drugs [10-11].Besides, oxime-ether derivatives are also widely used in agriculture as fungicides [12], herbicides [13], insecticides [14], and in the senescence of cut carnation flowers [15].

Because of the significance of oxime ethers as cited above, there is a continuous interest amidst the researchers to study the theoretical properties of the former [16-22]. All the above studies explored the features of the compounds associated with their reactivity, structure and advanced applications. Therefore in the present work, computational studies (based on Density Functional Theory) have been done for the methyl oxime ether derivative of piperidin-4-one. The various parameters, and properties such as optimized geometry, HOMO-LUMO visualization and their energy gap, ionization potential, electron affinity, global hardness, chemical potential, global electrophilicity index, Mulliken atomic charges have been calculated. The structural parameters such as bond lengths, bond angles and dihedral angles have been compared with the experimental values obtained from the earlier literature report by us [23].

Published By: 


\section{RESULTS AND DISCUSSION}

\section{A. Molecular geometry}

Computational study has been carried out using B3LYP/6-31G (d,p) in Gaussian 03 program. The full geometry optimization was carried out using 6-31G $(\mathrm{d}, \mathrm{p})$ basis set. The optimized geometry for the molecule predicted in the gas phase is shown in Fig. 1 and the optimization parameters such as bond lengths, bond angles and dihedral angles along with the experimental data obtained from $\mathrm{X}$-ray diffraction are given in Table $\mathbf{1 ,}, \mathbf{2} \& \mathbf{3}$ for comparative purpose.

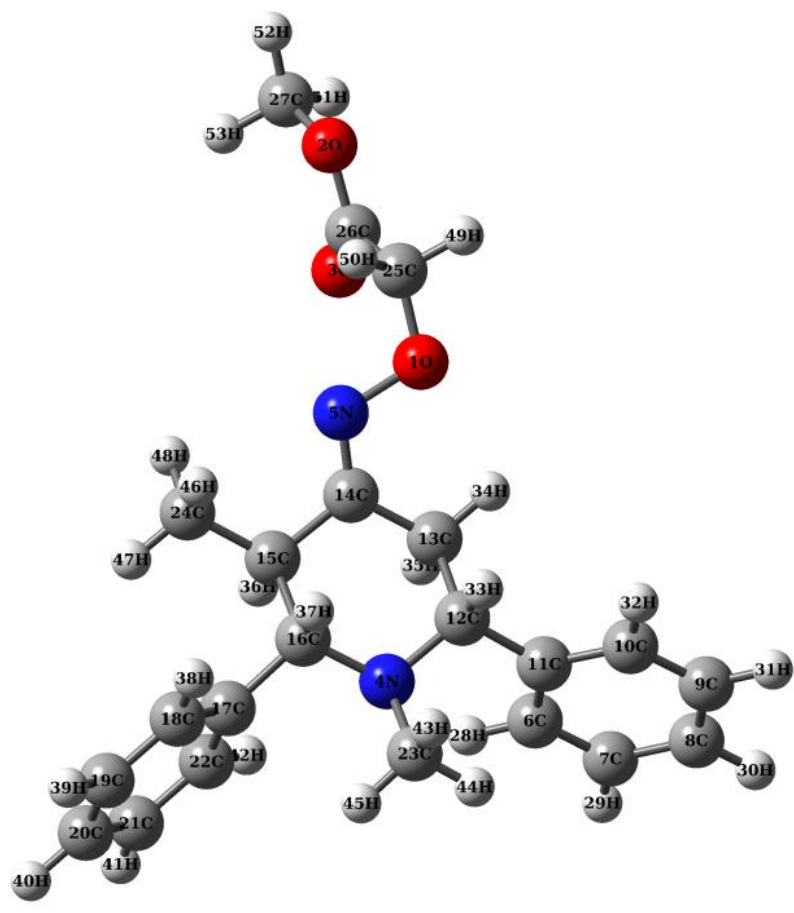

Fig. 1 Optimized geometry of the Oxime Ether

Table 1 Optimization parameters of Oxime Ether (Bond Lengths $\left({ }^{\circ}\right)$ )

\begin{tabular}{|l|l|l|l|l|l|}
\hline $\begin{array}{l}\text { Bond } \\
\text { length }\end{array}$ & Comp. & Expt. & $\begin{array}{l}\text { Bond } \\
\text { length }\end{array}$ & Comp. & Expt. \\
\hline O1-C25 & 1.4128 & $1.413(2)$ & C11-C12 & 1.5084 & $1.508(2)$ \\
\hline O2-C26 & 1.3388 & $1.339(3)$ & C12-C13 & 1.527 & $1.527(3)$ \\
\hline O2-C27 & 1.4339 & $1.434(3)$ & C13-C14 & 1.4858 & $1.486(3)$ \\
\hline O3-C26 & 1.1844 & $1.184(3)$ & C14-C15 & 1.49 & $1.490(3)$ \\
\hline N4-C12 & 1.4706 & $1.471(2)$ & C15-C16 & 1.5422 & $1.542(3)$ \\
\hline N4-C16 & 1.4688 & $1.469(2)$ & C15-C24 & 1.511 & $1.511(3)$ \\
\hline N4-C23 & 1.4672 & $1.467(3)$ & C16-C17 & 1.514 & $1.514(3)$ \\
\hline N5-C14 & 1.2719 & $1.272(2)$ & C17-C18 & 1.3709 & $1.371(3)$ \\
\hline C6-C7 & 1.3694 & $1.369(3)$ & C17-C22 & 1.388 & $1.388(3)$ \\
\hline C6-C11 & 1.383 & $1.383(3)$ & C18-C19 & 1.3884 & $1.388(4)$ \\
\hline C7-C8 & 1.3659 & $1.366(4)$ & C19-C20 & 1.3615 & $1.362(4)$ \\
\hline C8-C9 & 1.3554 & $1.355(4)$ & C20-C21 & 1.3764 & $1.376(5)$ \\
\hline C9-C10 & 1.3837 & $1.384(3)$ & C21-C22 & 1.3832 & $1.383(4)$ \\
\hline C10-C1 & 1.3808 & $1.381(3)$ & C25-C26 & 1.4952 & $1.495(3)$ \\
\hline 1
\end{tabular}

From the above said table, it is noticeable that there is considerable agreement between Computational and experimental values of most of $\mathrm{C}-\mathrm{C}, \mathrm{C}-\mathrm{N}$ and $\mathrm{C}-\mathrm{O}$ bond lengths and as for as the $\mathrm{C}-\mathrm{H}$ bonds considered in most cases the bond lengths are diminished by about $0.14 \AA$. There are several agreements/anomalies between the bond angles and dihedral angles of the optimized structure obtained by Computational study and that one proposed based on NMR spectra and by single crystal X-ray diffraction.

Despite some deviations in bond angles and dihedral angles, the stereochemical orientations of the substituents are not changed much. The variations observed between computational and experimental parameters could be understandable form the fact that in the solid state, intra as well as intermolecular interactions (such as hydrogen bonding and van der Waal's forces of attraction) play an important role in the molecular packing and stability of the molecule. Moreover, in the Computational study an isolated molecule in the gaseous state is considered for calculations.

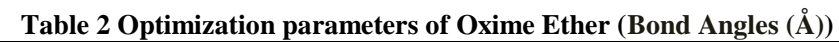

\begin{tabular}{|l|l|l|l|l|l|}
\hline Bond angle & Comp. & Expt. & Bond angle & Comp. & Expt. \\
\hline N5-O1-C25 & 108.332 & $108.3(1)$ & C13-C14-C15 & 114.0079 & $114.0(2)$ \\
\hline C26-O2-C27 & 117.5645 & $117.6(2)$ & C14-C15-C16 & 108.9303 & $108.9(1)$ \\
\hline C12-N4-C16 & 112.0594 & $112.1(1)$ & C14-C15-C24 & 114.4111 & $114.4(2)$ \\
\hline C12-N4-C23 & 108.7394 & $108.7(1)$ & C16-C15-C24 & 112.2351 & $112.2(2)$ \\
\hline C16-N4-C23 & 110.0465 & $110.0(1)$ & N4-C16-C15 & 111.5863 & $111.6(1)$ \\
\hline O1-N5-C14 & 109.9711 & $110.0(2)$ & N4-C16-C17 & 110.8342 & $110.8(1)$ \\
\hline C7-C6-C11 & 120.9041 & $120.9(2)$ & C15-C16-C17 & 110.6536 & $110.6(1)$ \\
\hline C6-C7-C8 & 120.4904 & $120.5(2)$ & C16-C17-C18 & 121.2778 & $121.3(2)$ \\
\hline C7-C8-C9 & 119.4491 & $119.5(2)$ & C16-C17-C22 & 120.4668 & $120.5(2)$ \\
\hline C8-C9-C10 & 120.9087 & $120.9(2)$ & C18-C17-C22 & 118.1871 & $118.2(2)$ \\
\hline C9-C10-C11 & 120.1062 & $120.1(2)$ & C17-C18-C19 & 121.2235 & $121.2(2)$ \\
\hline C6-C11-C10 & 118.1322 & $118.1(2)$ & C18-C19-C20 & 119.8743 & $119.9(2)$ \\
\hline C6-C11-C12 & 121.1467 & $121.1(2)$ & C19-C20-C21 & 120.1519 & $120.1(3)$ \\
\hline C10-C11-C12 & 120.654 & $120.6(2)$ & C20-C21-C22 & 119.7317 & $119.7(3)$ \\
\hline N4-C12-C11 & 112.0805 & $112.1(1)$ & C17-C22-C21 & 120.8292 & $120.8(2)$ \\
\hline N4-C12-C13 & 110.6753 & $110.7(1)$ & O1-C25-C26 & 113.0769 & $113.1(2)$ \\
\hline C11-C12-C13 & 108.9585 & $109.0(1)$ & O2-C26-O3 & 123.3392 & $123.3(2)$ \\
\hline C12-C13-C14 & 109.8857 & $109.9(1)$ & O2-C26-C25 & 109.4313 & $109.4(2)$ \\
\hline N5-C14-C13 & 126.7342 & $126.7(2)$ & O3-C26-C25 & 127.2192 & $127.2(2)$ \\
\hline N5-C14-C15 & 119.2255 & $119.2(2)$ & & & \\
\hline
\end{tabular}

\section{B. HOMO-LUMO energies}

The HOMO and LUMO energies calculated are $-5.9897 \mathrm{eV}$ and $0.3284 \mathrm{eV}$ respectively. The LUMO and HOMO are being measures of electron affinity (A) and ionization energy (I) as $-\mathrm{E}_{\mathrm{LUMO}}=\mathrm{A}$ and $-\mathrm{E}_{\mathrm{HOMO}}=\mathrm{I}$ respectively. The energy gap between the LUMO and HOMO is also indicative of the global hardness $(\eta=$ $\left.1 / 2\left[\mathrm{E}_{\mathrm{LUMO}}-\mathrm{E}_{\mathrm{HOMO}}\right]\right)$ which is associated with the stability of the system while the term chemical potential $(\mu)$ is given by $1 / 2\left[\mathrm{E}_{\mathrm{LUMO}}+\mathrm{E}_{\mathrm{HOMO}}\right]$. Further, the global electrophilicity index $(\omega)$ is derived from the relation $\omega=\mu^{2} / 2 \eta$. The above molecular properties calculated are depicted in Table 4.

The energy gap between the HOMO and the LUMO is $5.6613 \mathrm{eV}$ which suggests that the molecule is soft, more polarizable, associated with appreciable chemical reactivity. Moreover,

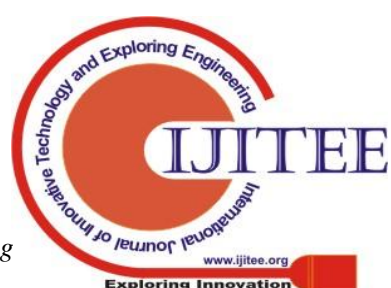


the HOMO and LUMO energy gap explains the eventual charge transfer interactions that take place within the molecule which are responsible for the bioactivity of the molecule. It is observed from the HOMO and LUMO orbital diagrams (Fig. 2) that in the HOMO, the electron density is localized mainly in the phenyl rings attached to the $\mathrm{C} 2, \mathrm{C} 6$ carbons and the piperidine ring while in the LUMO; the electron density is distributed mainly over the piperidine ring and also over the oxime ether moiety. This indicates that the HOMO is having contribution from mostly the $\pi$-type orbitals of aromatic rings and the LUMO is devoid of the contribution from $\pi$-type orbitals. Therefore when electronic transitions occur from HOMO to LUMO in the molecule, electron density significantly decreases in the electron-donating benzene ring systems and result in an increase in the oxime ether moiety which behaves as an electron acceptor in the molecule.

Table 30ptimization parameters of Oxime Ether (Torsion Angles $\left(^{\circ}\right)$ )

\begin{tabular}{|c|c|c|c|c|c|}
\hline Torsion angle & Comp. & Expt. & Torsion angle & Comp. & Expt. \\
\hline C25-O1-N5-C14 & -172.815 & $\begin{array}{l}-172.8(2 \\
{ }^{2}\end{array}$ & N4-C12-C13-C14 & 55.1838 & $55.2(2)$ \\
\hline N5-O1-C25-C26 & -71.8869 & $-71.9(2)$ & C11-C12-C13-C14 & 178.8577 & $178.9(1)$ \\
\hline $\mathrm{C} 27-\mathrm{O} 2-\mathrm{C} 26-\mathrm{O} 3$ & 1.6574 & $1.7(3)$ & $\mathrm{C} 12-\mathrm{C} 13-\mathrm{C} 14-\mathrm{N} 5$ & 122.6649 & $122.7(2)$ \\
\hline $\mathrm{C} 27-\mathrm{O} 2-\mathrm{C} 26-\mathrm{C} 25$ & -179.437 & $\begin{array}{l}-179.4(2 \\
\text { (2) }\end{array}$ & C12-C13-C14-C15 & -55.2319 & $-55.2(2)$ \\
\hline C16-N4-C12-C11 & -179.501 & $\begin{array}{l}-179.5(1 \\
\end{array}$ & N5-C14-C15-C16 & -124.122 & $\begin{array}{l}-124.1(2 \\
{ }^{2}\end{array}$ \\
\hline C16-N4-C12-C13 & -57.6431 & $-57.6(2)$ & N5-C14-C15-C24 & 2.3884 & $2.4(2)$ \\
\hline C23-N4-C12-C11 & 58.6259 & $58.6(2)$ & C13-C14-C15-C16 & 53.9463 & $53.9(2)$ \\
\hline C23-N4-C12-C13 & -179.516 & $\begin{array}{l}-179.5(2 \\
{ }^{2}\end{array}$ & $\mathrm{C} 13-\mathrm{C} 14-\mathrm{C} 15-\mathrm{C} 24$ & -179.543 & $\begin{array}{l}-179.5(2 \\
{ }^{2}\end{array}$ \\
\hline C12-N4-C16-C15 & 57.3397 & $57.3(2)$ & $\mathrm{C} 14-\mathrm{C} 15-\mathrm{C} 16-\mathrm{N} 4$ & -53.7678 & $-53.8(2)$ \\
\hline C12-N4-C16-C17 & -178.852 & $\begin{array}{l}-178.9(1 \\
\end{array}$ & C14-C15-C16-C17 & -177.679 & $\begin{array}{l}-177.7(2 \\
{ }^{2}\end{array}$ \\
\hline C23-N4-C16-C15 & 178.4617 & $178.5(1)$ & $\mathrm{C} 24-\mathrm{C} 15-\mathrm{C} 16-\mathrm{N} 4$ & 178.4821 & $178.5(2)$ \\
\hline C23-N4-C16-C17 & -57.7295 & $-57.7(2)$ & C24-C15-C16-C17 & 54.5714 & $54.6(2)$ \\
\hline O1-N5-C14-C13 & 3.254 & $3.3(3)$ & N4-C16-C17-C18 & 125.0251 & $125.0(2)$ \\
\hline O1-N5-C14-C15 & -178.948 & $\begin{array}{l}-178.9(1 \\
)^{-1}\end{array}$ & N4-C16-C17-C22 & -58.0351 & $-58.0(2)$ \\
\hline C11-C6-C7-C8 & 0.7656 & $0.8(4)$ & C15-C16-C17-C18 & -110.634 & $\begin{array}{l}-110.6(2 \\
{ }^{2}\end{array}$ \\
\hline C7-C6-C11-C10 & -0.5546 & $-0.6(3)$ & $\mathrm{C} 15-\mathrm{C} 16-\mathrm{C} 17-\mathrm{C} 22$ & 66.3063 & $66.3(2)$ \\
\hline C7-C6-C11-C12 & 176.4848 & $176.5(2)$ & C16-C17-C18-C19 & 177.2413 & $177.2(2)$ \\
\hline C6-C7-C8-C9 & -0.0956 & $-0.1(4)$ & C22-C17-C18-C19 & 0.2338 & $0.2(3)$ \\
\hline C7-C8-C9-C10 & -0.7682 & $-0.8(4)$ & $\mathrm{C} 16-\mathrm{C} 17-\mathrm{C} 22-\mathrm{C} 21$ & -176.821 & $\begin{array}{l}-176.8(2 \\
)^{2}\end{array}$ \\
\hline C8-C9-C10-C11 & 0.9713 & $1.0(4)$ & $\mathrm{C} 18-\mathrm{C} 17-\mathrm{C} 22-\mathrm{C} 21$ & 0.2115 & $0.2(3)$ \\
\hline C9-C10-C11-C6 & -0.2997 & $-0.3(3)$ & $\mathrm{C} 17-\mathrm{C} 18-\mathrm{C} 19-\mathrm{C} 20$ & -0.4559 & $-0.5(4)$ \\
\hline C9-C10-C11-C12 & -177.354 & $\begin{array}{l}-177.4(2 \\
)\end{array}$ & $\mathrm{C} 18-\mathrm{C} 19-\mathrm{C} 20-\mathrm{C} 21$ & 0.2247 & $0.2(4)$ \\
\hline C6-C11-C12-N4 & 51.3325 & $51.3(2)$ & C19-C20-C21-C22 & 0.2138 & $0.2(4)$ \\
\hline C6-C11-C12-C13 & -71.5025 & $-71.5(2)$ & C20-C21-C22-C17 & -0.4373 & $-0.4(4)$ \\
\hline C10-C11-C12-N4 & -131.703 & $\begin{array}{l}-131.7(2 \\
{ }^{2}\end{array}$ & $\mathrm{O} 1-\mathrm{C} 25-\mathrm{C} 26-\mathrm{O} 2$ & 175.58 & $175.6(2)$ \\
\hline $\mathrm{C} 10-\mathrm{C} 11-\mathrm{C} 12-\mathrm{C} 13$ & 105.4625 & $105.5(2)$ & $\mathrm{O} 1-\mathrm{C} 25-\mathrm{C} 26-\mathrm{O} 3$ & -5.5676 & $-5.6(3)$ \\
\hline
\end{tabular}

\section{Highest Occupied Molecular Orbital} (HOMO):
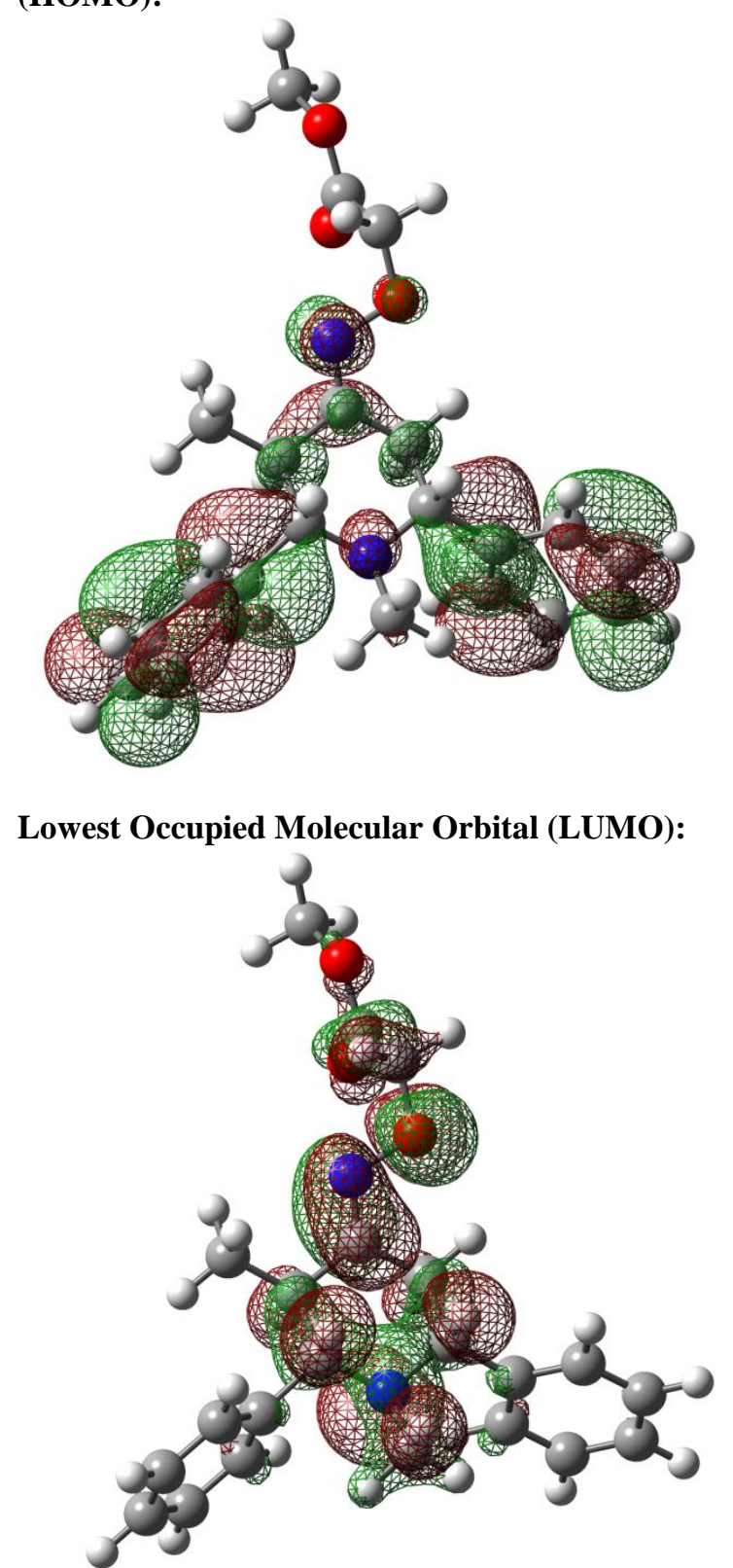

Fig. 2 HOMO and LUMO diagrams of Oxime Ether \& Sciences Publication 


\section{C. $\quad$ NLO properties}

The NLO properties such as dipole moment, polarizability and hyperpolarizability calculated by computational study are shown in Table 5. The dipole moment value equal to $0.9791 \mathrm{D}$ indicates the polar nature of the molecule. The highest value of dipole moment is observed for the component $\mu_{\mathrm{x}}(0.2541)$ in the molecule. The calculated polarizability is higher for the component $\alpha_{x y}(-0.6498)$ and the hyperpolarizability is higher for the $\beta_{\mathrm{xxx}}$ (247.8589) component. It is interesting to note that the calculated polarizability $(\alpha)$ value for the oxime ether is equal to $-0.6498 \times 10^{-18}$ e.s.u. which is almost four times greater than that of $p$-nitroaniline, a typical NLO material [24-25]. Also the comparison of hyperpolarizability $\left(\beta, 247.8589 \times 10^{-18}\right.$ e.s.u.) of the oxime ether (which is twice that of the standard NLO material urea, $\beta=0.72137 \times 10^{-30}$ e.s.u.) reveals that the former could be used an effective NLO material.

Table 5 NLO properties of the Oxime Ether

\begin{tabular}{|l|l|l|l|}
\hline \multicolumn{2}{|l|}{ Polarizability } & \multicolumn{2}{l|}{ Hyperpolarizability } \\
\hline$\alpha_{\mathrm{xx}}$ & -139.5246 & $\beta \mathrm{xxx}$ & 247.8589 \\
\hline$\alpha_{\mathrm{yy}}$ & -149.0363 & $\beta \mathrm{xxy}$ & -49.1473 \\
\hline$\alpha_{\mathrm{zz}}$ & -153.5783 & $\beta \mathrm{xyy}$ & -6.3071 \\
\hline \multirow{2}{*}{$\alpha_{\text {total }}-442.1392$} & $\beta \mathrm{yyy}$ & 23.5407 \\
\cline { 3 - 4 } & \multirow{2}{*}{ Dipole moment } & $\beta \mathrm{xxz}$ & 26.7375 \\
\cline { 3 - 4 } & & $\beta \mathrm{yyyz}$ & -17.6307 \\
\hline $\mathrm{X}$ & 0.2541 & $\beta \mathrm{xzz}$ & -7.7219 \\
\hline $\mathrm{Y}$ & -0.2549 & $\beta \mathrm{yzz}$ & -0.7467 \\
\hline $\mathrm{Z}$ & -0.9105 & $\beta \mathrm{zzz}$ & -0.0765 \\
\hline Total & 0.9791 & $\beta_{\text {Total }}$ & 221.5353 \\
\hline
\end{tabular}

\section{Atomic charge distribution}

The charge distribution on a molecule has a significant influence on dipole moment, molecular polarizability, electronic structure, vibrational spectra and other properties of molecular systems. Mulliken atomic charge distribution is calculated for the oxime ether and the table summarizing the charge distribution is given along with the graph explaining the same pictorially (Table 6 and Fig. 3). It is seen from the graph that the heteroatoms $\mathrm{O} 1, \mathrm{O} 2, \mathrm{O} 3$, $\mathrm{N} 4, \mathrm{~N} 5$ and carbon atoms $\mathrm{C} 13, \mathrm{C} 23$ and $\mathrm{C} 24$ are accumulated with negative charges as a result of molecular relaxation and these atoms behave as electron acceptors. There is a large accumulation of positive charge on C14 \& C26 and a large negative charge on $\mathrm{O} 2 \& \mathrm{O} 3$ atoms. It is also notable that both oxygen and nitrogen atoms are having equal negative charges. The excess is taken from the nearby carbon and hydrogen atoms and as a result of this they are found with positive sign in the graph. Further, most of the carbon atoms are negatively charged indicating that there are charge transfers occurred from hydrogen atoms to carbon atoms in the molecule.

Table 6 Mulliken Atomic Charge distribution

\begin{tabular}{|c|c|c|c|}
\hline \multicolumn{1}{|l|}{ tom } & Charges & Atom & Charges \\
\hline O1 & -0.39132 & H28 & 0.094216 \\
\hline O2 & -0.46297 & H29 & 0.085461 \\
\hline O3 & -0.4611 & H30 & 0.084195 \\
\hline N4 & -0.45141 & H31 & 0.084983 \\
\hline N5 & -0.23752 & H32 & 0.081632 \\
\hline
\end{tabular}

\begin{tabular}{|l|l|l|l|}
\hline C6 & -0.10324 & $\mathrm{H} 33$ & 0.073021 \\
\hline C7 & -0.08796 & $\mathrm{H} 34$ & 0.139102 \\
\hline C8 & -0.08444 & $\mathrm{H} 35$ & 0.12327 \\
\hline C10 & -0.08695 & $\mathrm{H} 36$ & 0.110693 \\
\hline C11 & 0.12087 & $\mathrm{H} 37$ & 0.068183 \\
\hline C12 & 0.0354118 & $\mathrm{H} 38$ & 0.082344 \\
\hline C13 & -0.20582 & $\mathrm{H} 39$ & 0.085553 \\
\hline C14 & 0.295929 & $\mathrm{H} 41$ & 0.084864 \\
\hline C15 & -0.10334 & $\mathrm{H} 42$ & 0.085939 \\
\hline C17 & 0.047585 & $\mathrm{H} 43$ & 0.0785839 \\
\hline C18 & -0.086688 & $\mathrm{H} 44$ & 0.121308 \\
\hline C19 & -0.08682 & $\mathrm{H} 46$ & 0.107819 \\
\hline C20 & -0.0851 & $\mathrm{H} 47$ & 0.109931 \\
\hline C21 & -0.08836 & $\mathrm{H} 48$ & 0.120201 \\
\hline C22 & -0.10159 & $\mathrm{H} 49$ & 0.137385 \\
\hline C23 & -0.17097 & $\mathrm{H} 50$ & 0.135482 \\
\hline C24 & -0.31251 & $\mathrm{H} 51$ & 0.130419 \\
\hline C25 & 0.006564 & $\mathrm{H} 52$ & 0.120811 \\
\hline C26 & 0.591771 & $\mathrm{H} 53$ & 0.132769 \\
\hline C27 & -0.08354 & & \\
\hline & & & \\
\hline
\end{tabular}

\section{EXPERIMENTAL}

Computational calculations were done by considering the crystal structure of oxime ether as the initial structure using B3YLP/DFT methods using 6-31G (d, p) as the basis set in Gaussian 03 package [26] to optimize the structure. The lowest unoccupied molecular orbital (LUMO) and highest occupied molecular orbital (HOMO) energy differences for the molecule were calculated with these methods. The other properties like bond lengths, bond angles, dihedral angles, dipole moment, polarizability, hyperpolarizability and Mulliken charge distribution pattern and some other important molecular properties are also calculated using the same package. Gauss View program is used to visualize the results obtained from calculations, which were made by Gaussian 03 program.

\section{CONCLUSION}

Computational studies using Density Functional Theory (DFT) has been done to get optimized structure, HOMO-LUMO energies, dipole moment values etc. Anomalies between the experimental and computational values of optimized structure could be accounted by the difference in their physical state.

HOMO-LUMO energy gap of the oxime ether corresponds to about $5.6613 \mathrm{eV}$ and this energy gap provides stability of the molecule. The dipole moment value suggests that the probable use of the compound as a NLO material. The Mulliken population analysis revealed the electrophilic and nucleophilic centres present in the molecule.

Blue Eyes Intelligence Engineering

\& Sciences Publication 


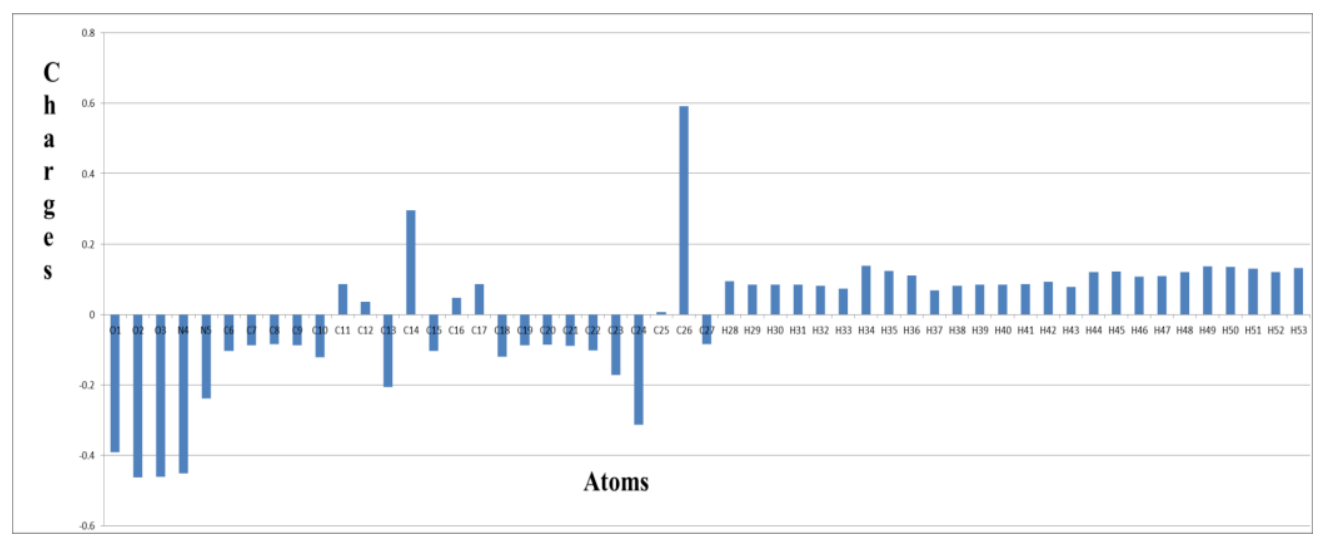

Fig 3 Mulliken Atomic Charge distribution

\section{REFERENCES}

[1] M. Makosa, "Phase-transfer catalysis. A general green methodology in organic synthesis", Pure Appl. Chem., Vol. 72, No. 7, pp. 1399-1403, 2000 .

[2] W. F. M. Van Brewer, C. J. E. Niemegeers, K. H. L. Schellenken, P. A. J. Janssen, 1-(2-arylethyl)-4-piperidinyl-N-phenylpropanamides, a novel series of extremely potent analgesics with unusually high safety margin", Arzneimittel-Forschung, vol. 26(8), pp. 1548-1551, Jan 1976.

[3] H. I. El-Subbagh, S. M. Abu-Zaid, M. A. Mahran, F. A. Badria, A. M. Al-Obaid, "Synthesis and Biological Evaluation of Certain $\alpha, \beta$-Unsaturated Ketones and Their Corresponding Fused Pyridines as Antiviral and Cytotoxic Agents", J. Med. Chem.,vol. 43(15), pp. 2915-2921, July 2000.

[4] A. A. Watson, G. W. J. Fleet, N. Asano, R. J. Molyneux, R. J. Nash, "Polyhydroxylated alkaloids - natural occurrence and therapeutic applications",Phytochemistry, vol. 56(3), pp. 265-295, February 2001.

[5] C. R. Ganellin, R. G. W. Spickett, "Compounds Affecting the Central Nervous System. I. 4-Piperidones and Related Compounds", J. Med. Chem., vol. 8(5), pp. 619-625, September 1965.

[6] R. E. Hagenbach, H. Gysin, "Über einige heterozyklische Thiosemicarbazone", Experientia 8(5), pp. 184-185, May 1952.

[7] I. Baracu, V. Dobre, I. Niculescu-Duvaz, "Potential anticancer agents. XXVI亡. Spin Labelled Nitrosoureas”, J. Prakt. Chem., vol. 327(4), pp.

[8] I.G. Mokio, A.T. Soldatenkov, V.O. Federov, Ageev, E.A.; N.D. Sergeeva, S. Lin, E.E. Stashenku, N.S. Prostakov, E.L. Andreeva, "Antimicrobial activity of aliphatic-aromatic ketones, $\beta$-ketols and aglycols", Khim. Farm Zh., vol. 23, pp. 421-427, 1989.

[9] E. Abele, E. Lukevics, "Recent Advances in the Chemistry of Oximes”, Org. Prep. Proc., Int. vol. 32(3), pp. 235-264, April 2000.

[10] V. A. Polyakov, M. I. Nelen, N. Nazarpack-Kandlousy, A. D. Ryabov, A. V. Eliseev, "Imine exchange in $O$-aryl and $O$-alkyl oximes as a base reaction for aqueous 'dynamic' combinatorial libraries. A kinetic and thermodynamic study”, J. Phys. Org. Chem., 12(5), pp. 357-363, May 1999.

[11] M. I. Wilde, G. L. Plasker, P. Benfield, "Fluvoxamine", Drugs, vol. 46 (5), pp. 895-924, November 1993.

[12] X. Zhu, D. Shi, "Synthesis and Biological Activities of Novel Thiophosphoryl Oximates Containing Thiazole and 1,2,3-Triazole Rings", Chin. J. Chem., vol. 27(3), pp. 565-568, 2009.

[13] L. Chen, J. H. Yao, L. P. Yuan, J. Cao, Y. Huang, W. Xie, C.Ni, C. Shen, Z. Li, X. L. Zhang, Y. B. "Synthesis and Molecular Design of Acetophenone Oxime Derivatives Based on Quantitative Structure-Activity Relationship", Acta Chim. Sinica, vol. 65(22), pp. 2583-2591, September 2007.

[14] L. Z. Ling, A. P. Liu, C. Chen, Z. Z. Wei, D. S. Wang, D. L. Yin, X. G. Wang, "Synthesis and Biological Activity of Oxime Ethers Containing Indanone",Chin. J. Pestic. Sci. vol. 1, pp. 25-29, 2006.

[15] Z. Zeng, H. Jiang, H. Zhang, Z. Jiang, "The synthesis of novel oxime ethers and their effects on the senescence of cut carnation flowers", Res. Chem. Intermed. 38(2), pp. 463-470, February 2012.

[16] Z. S. Şahin, Z. Özdemir, A. Karakurt, Ş. Işik, “An X-ray and DFT Computational Study on 1-(Naphthalene-2-yl)-2-(1H-pyrazol-1-yl)
"N-4-Substituted 667-674, 1985.

ethanone O-butyl Oxime", Chinese J. Struct. Chem., vol. 31(2), pp 262-270, January 2012.

[17] C.F. Tormena, R. Rittner, R. J. Abraham, E. A. Basso, B. C. Fiori, "Conformational analysis of fluoroacetoxime and of its $O$-methyl ether by ${ }^{1} \mathrm{H},{ }^{13} \mathrm{C}$ and ${ }^{15} \mathrm{~N}$ NMR and theoretical calculations", J. Phys. Org. Chem., vol. 17(1), pp. 42-48, January 2004.

[18] M. Alam, Dong-Ung Le, "Eco-Friendly Synthesis, Physicochemical Studies, Biological Assay and Molecular Docking of Steroidal Oxime-Ethers", EXCLI Journal, vol. 14, pp.394-407, March 2015.

[19] Igor Picek, Robert Vianello, Primoz Sket, Janez Plavec, Blaženka Foreti, "Tandem $\quad \beta$-Elimination/Hetero-Michael Addition Rearrangement of an N-Alkylated Pyridinium Oxime to an O-Alkylated Pyridine Oxime Ether: An Experimental and Computational Study", J. Org. Chem. 80(4), pp. 2165-2173, January 2015.

[20] T. Dey, K. S. S. Praveena, S. Pal, A. K. Mukherjee, "Three Oxime Ether Derivatives: Synthesis, Crystallographic Study, Electronic Structure and Molecular Electrostatic Potential Calculation", J. Mol Struct., Vol. 1137, pp. 615-625, June 2017

[21] A. Manimekalai, S. Sivakumar, "Synthesis, Spectral and Computational Studies of Some $N$-Acyl-t(3)-isopropyl-r(2), $c$ (6)-bis-2-Furylpiperidin-4-one Oximes", Spectrochimica Acta Part A., vol. 75(1), pp. 113-120, January 2010.

[22] G. Sundararajan, D. Rajaraman, T. Srinivasan, D. Velmurugan, K. Krishnasamy, "Synthesis, Characterization, Computational Calculation and Biological Studies of Some 2,6-Diaryl-1-(prop-2-yn-1-yl)piperidin-4-one Oxime Derivatives", Spectrochimica Acta Part A, vol. 139, pp. 108-118, March 2015.

[23] M.Velayutham Pillai, K.Rajeswari, T.Vidhyasagar, "Synthesis, Spectral and Single Crystal X-Ray Diffraction Studies of Novel $O$-(Carboalkoxy)methyl Oxime Ethers of 3-Alkyl and 3,5-Dialkyl-1-methyl-2,6-diphenylpiperidin-4-ones”, J. Mol. Struct. 1076, pp. 94-104, 2014.

[24] L. T. Cheng, W. Tam, S. H. Stevenson, G. R. Meredith, G. Rikken, S. R. Marder, "Experimental Investigations of Organic Molecular Nonlinear Optical Polarizabilities. 1. Methods and Results on Benzene and Stilbene Derivatives”, J. Phys. Chem., Vol.95, pp. 10631-10643, December 1991.

[25] P. Kaatz, E. A. Donley, D. P. Shelton, “A Comparison of Molecular Hyperpolarizabilities from Gas and Liquid Phase Measurements", J. Chem. Phys., vol. 108(3), pp. 849-856, January 1998.

[26] M. J. Frisch, G. W. Trucks, H. B. Schlegel, G. E. Scuseria, M. A. Robb J. R. Cheeseman, J. A. Montgomery, Jr., T. Vreven, K. N. Kudin, J. C. Burant, J. M. Millam, S. S. Iyengar, J. Tomasi, V. Barone, B. Mennucci, M. Cossi, G. Scalmani, N. Rega, G. A. Petersson, H. Nakatsuji, M. Hada, M. Ehara, K. Toyota, R. Fukuda, J. Hasegawa, M. Ishida, T. Nakajima, Y. Honda, O. Kitao, H. Nakai, M. Klene, X. Li, J. E. Knox, H. P. Hratchian, J. B. Cross, V. Bakken, C. Adamo, J. Jaramillo, R. Gomperts, R. E. Stratmann, O. Yazyev, A. J. Austin, R. Cammi, C. Pomelli, J. W. Ochterski, P. Y. Ayala, K. Morokuma, G. A Voth, P. Salvador, J. J. Dannenberg, V. G. Zakrzewski, S. Dapprich, A D. Daniels, M. C. Strain, O. Farkas, D. K. Malick, A. D. Rabuck, K Raghavachari, J. B. Foresman, J. V. Ortiz, Q. Cui, A. G. Baboul, S. Clifford, J. Cioslowski, B. B. Stefanov, G. Liu, 
A. Liashenko, P. Piskorz, I. Komaromi, R. L. Martin, D. J. Fox, T. Keith, M. A. Al-Laham, C. Y. Peng, A. Nanayakkara, M. Challacombe, P. M. W. Gill, B. Johnson, W. Chen, M. W. Wong, C. Gonzalez, and J. A. Pople, Gaussian 03, Revision D.01, Gaussian, Inc., Wallingford CT, (2004)

\section{AUTHORS PROFILE}
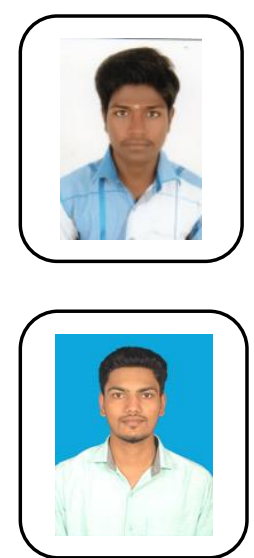

B. Siva Prakash, currently pursuing post graduate degree in Chemistry at Kalasalingam University (KLU), Krishnankovil. He completed his undergraduation in Chemistry from KLU during May 2019. His research interests include Organic Synthesis, Stereochemistry and Spectral Studies of bioactive molecules.

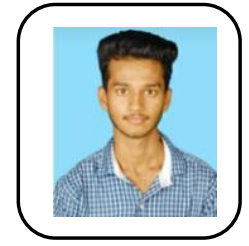

M. Thillai Natarajan, currently pursuing pos graduate degree in Chemistry at Bharathiar University, Coimbatore. He completed his undergraduation in Chemistry from KLU during May 2019. His research interests include Organic Synthesis and Quantum Chemical Studies of bioactive molecules.

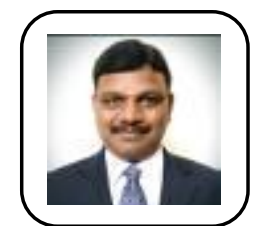

Dr. Chennan Ramalingan is serving as Professor of Chemistry at KARE. He received PhD in Organic Chemistry from Annamalai University in 2002. After he served as Research Professor at Kyungpook National University, South Korea followed by Assistant Professor at Osaka University, Japan, he joined at Kalasalingam Academy of Research and Education, Krishnankoil in late 2011. His research interests include organic synthesis, medicinal chemistry and material chemistry. He published more than 70 International research articles

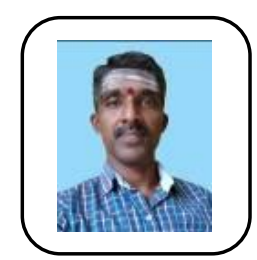

Dr. M. Velayutham Pillai had his under graduate education from Christian College, Nagercoil (1995-'97) and pursued doctoral research in Organic Chemistry at Annamalai University (2010-`14). He has published 14 research articles in peer-reviewed, indexed journals with good impact factor (Total citations: $17, h$-index: 2 ). His area of research are Organic Synthesis, Spectral Studies, Single Crystal X-ray diffraction Studies and Computational Chemistry. Presently he is working as Assistant Professor of Chemistry at Kalasalingam University, Krishnankovil (Tamil Nadu). He is a Life Member of Association of Environmental Analytical Chemistry of India (AEACI), Indian Science Congress Association (ISCA), Association of Separation Scientists and Technologists (ASSET), Indian Crystallographic Association (ICA) and Chromatographic Society of India (CSI). 